\title{
Sneddon Syndrome without Antiphospholipid Antibodies
}

\author{
Ziani J*, Douhi Z, Bennani M, Elloudi S, Baybay H and Mernissi FZ
}

Department of dermatology, Hassan II hospital university, Fez, Morocco

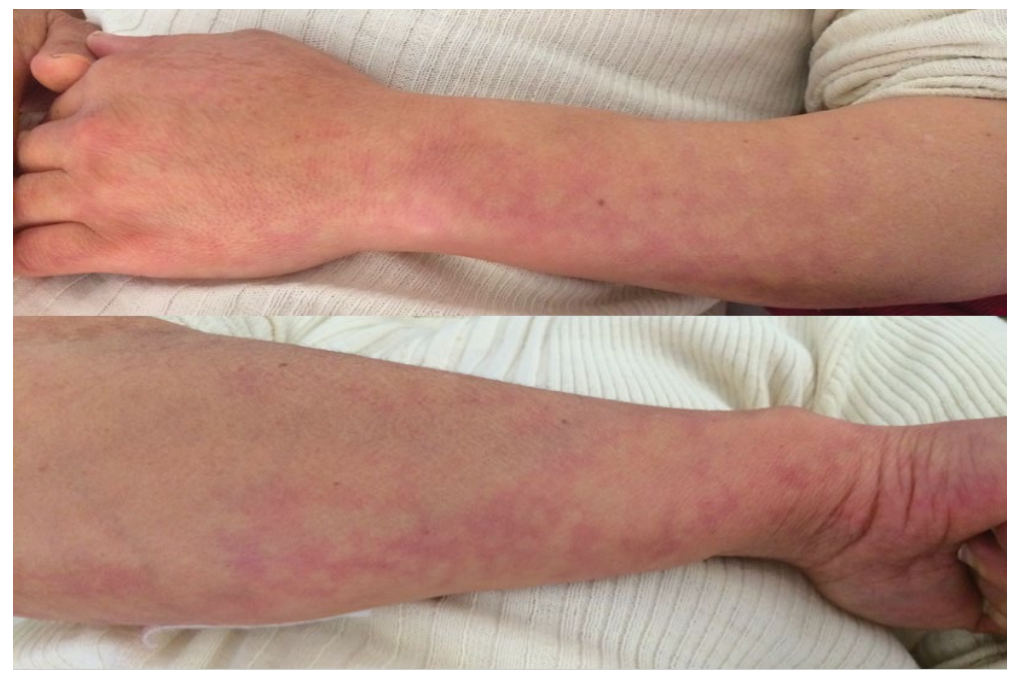

Figure 1: Sneddon syndrome.

\section{Clinical Image}

Madame $F, 55$ years old with a story; four miscarriages and two fetal deaths in utero. At 40 years old, she had a brutal motor deficit in the left lower limb and then in the homolateral upper limb associated with left hemifacialparaesthesia with complete recovery 10 years ago. She was readmitted for the installation of a left hemiplegia, a left central facial paralysis, a dysarthria with a NIH score of 9 associated with a livemedracemosis, branched, with large irregular open meshes, asymmetric diffusion affecting the legs; thighs, legs and feet. The brain scan shows an infarction of the superficial territory of the right Sylvian artery. On the balance sheet a negative determination of anti-phospholipid antibodies. The diagnosis of Sneddon syndrome is retained, the NIH score rose to 2 under curative anticoagulation followed by secondary prevention. Sneddon syndrome is a rare disease of unknown cause. Its frequency is difficult to estimate and seems underestimated [1]. It is characterized by the association of reticular and cerebrovascular accidents, sometimes responsible for deficits. The other neurological manifestations are polymorphic: headache, epilepsy, paraesthesia, dizziness, facial paralysis, pseudo-bulbar syndrome, long-term dementia. Biologically, antiphospholipid antibodies (APL) are found in $40 \%$ of cases [2].

The occurrence of a stroke in young people, especially in the presence of a racemosalivedo, should suggest the diagnosis of Sneddon syndrome (Figure 1).

\section{Conflicts of Interest}

Author declares that there is no conflict of interest.

\section{References}

1. Burton, JL. "Livedo Reticularis, Porcelain-White Scars, and Cerebral Thrombosis". Lancet 331 (1988): 1263-1265.

2. Frances, Camille. 'Dermatological Manifestations of Hughes' Antiphospholipid Antibody Syndrome". Medicine 52 (1999): 1785-1793.1785-1793.

How to cite this article: Ziani J, Douhi Z, Bennani M and Elloudi S, et al."Sneddon Syndrome without Antiphospholipid Antibodies." J Mol Genet Med 14 (2020): 446 doi: 10.37421/jmgm.2020.14.446 